\title{
Phase-contrast MRI volume flow - a comparison of breath held and navigator based acquisitions
}

\author{
Charlotta Andersson 1,2, Johan Kihlberg ${ }^{1,3}$, Tino Ebbers ${ }^{1}$, Lena Lindström², Carl-Johan Carlhäll ${ }^{1,4,5}$ \\ and Jan E. Engvall ${ }^{1,4,5^{*}}$
}

\begin{abstract}
Background: Magnetic Resonance Imaging (MRI) 2D phase-contrast flow measurement has been regarded as the gold standard in blood flow measurements and can be performed with free breathing or breath held techniques. We hypothesized that the accuracy of flow measurements obtained with segmented phase-contrast during breath holding, and in particular higher number of k-space segments, would be non-inferior compared to navigator phase-contrast. Volumes obtained from anatomic segmentation of cine MRI and Doppler echocardiography were used for additional reference.
\end{abstract}

Methods: Forty patients, five women and 35 men, mean age 65 years (range 53-80), were randomly selected and consented to the study. All underwent EKG-gated cardiac MRI including breath hold cine, navigator based free-breathing phase-contrast MRI and breath hold phase-contrast MRI using k-space segmentation factors 3 and 5 , as well as transthoracic echocardiography within 2 days.

Results: In navigator based free-breathing phase-contrast flow, mean stroke volume and cardiac output were $79.7 \pm 17.1 \mathrm{ml}$ and $5071 \pm 1192 \mathrm{ml} / \mathrm{min}$, respectively. The duration of the acquisition was $50 \pm 6 \mathrm{~s}$. With $\mathrm{k}$-space segmentation factor 3 , the corresponding values were $77.7 \mathrm{ml} \pm 17.5 \mathrm{ml}$ and $4979 \pm 1211 \mathrm{ml} / \mathrm{min}(p=0.15 \mathrm{vs}$ navigator). The duration of the breath hold was $17 \pm 2 \mathrm{~s}$. K-space segmentation factor 5 gave mean stroke volume $77.9 \pm 16.4 \mathrm{ml}$, cardiac output $5142 \pm 1197 \mathrm{ml} / \mathrm{min}$ ( $p=0.33$ vs navigator), and breath hold time $11 \pm 1 \mathrm{~s}$. Anatomical segmentation of cine gave mean stroke volume and cardiac output $91.2 \pm 20.8 \mathrm{ml}$ and $5963 \pm 1452 \mathrm{ml} / \mathrm{min}$, respectively. Echocardiography was reliable in 20 of the 40 patients. The mean diameter of the left ventricular outflow tract was $20.7 \pm 1.5 \mathrm{~mm}$, stroke volume $78.3 \mathrm{ml} \pm 15.2 \mathrm{ml}$ and cardiac output $5164 \pm 1249 \mathrm{ml} / \mathrm{min}$.

Conclusions: In forty consecutive patients with coronary heart disease, breath holding and segmented k-space sampling techniques for phase-contrast flow produced stroke volumes and cardiac outputs similar to those obtained with free-breathing navigator based phase-contrast MRI, using less time. The values obtained agreed fairly well with Doppler echocardiography while there was a larger difference when compared with anatomical volume determinations using SSFP (steady state free precession) cine MRI.

Keywords: Phase-contrast flow, Magnetic resonance imaging, Segmentation, 2D Doppler echocardiography

\footnotetext{
* Correspondence: jan.engvall@regionostergotland.se

${ }^{1}$ Center for Medical Image Science and Visualization, Linkoping University,

SE-581 83 Linkoping, Sweden

${ }^{4}$ Department of Medical and Health Sciences, Linkoping University, SE-581 83

Linkoping, Sweden

Full list of author information is available at the end of the article
} 


\section{Background}

The generation of cardiovascular flow has been said to be the essence of cardiology [1]. Unfortunately, in clinical practice, the applicability of methods used to determine flow may be restricted by the pre-existing condition of the patient. Various techniques have been favoured and later abandoned such as indicator dilution with indocyanine green, while others, e.g. thermodilution, have withstood the test of time. Completely non-invasive determination of stroke volume with echocardiography and Doppler recording is versatile and readily available at the bedside, but the calculation rests on a number of assumptions such as a circular geometry of the left ventricular outflow tract [2] and a spatially flat flow profile [3]. MRI phase-contrast flow measurement has been regarded as the gold standard since it can address issues of temporally as well as spatially varying flows $[4,5]$. However, MRI velocity measurements are sensitive to magnetic field inhomogeneities, concomitant gradient effects, and eddy current effects that are only partly compensated for [6]. Gatehouse suggested that an error of $5 \%$ could be acceptable in clinical practice, which would be equivalent to $4 \mathrm{ml}$ when the stroke volume is $80 \mathrm{ml}$ and $250 \mathrm{ml}$ when cardiac output is $5000 \mathrm{ml} / \mathrm{min}$ [7]. Previous work has suggested that the size of the great vessels is the most important factor that determines baseline phase offset [8]. Furthermore, MRI collects flow data from several heart beats and cannot measure beat-by-beat variation, except when using techniques of reduced sampling such as the pencil beam technique for real-time flow velocity [9]. In busy daily practice, sampling is performed during a short breath hold that may introduce some errors due to physiological effects on cardiac filling and effects of averaging when using segmented k-space sampling methods [10-12]. The extent of these effects is influenced by the length of the breath holding, which in its turn depends on heart rate and scanner settings. To avoid the physiological effects of holding breath, the obvious alternative would be sampling during free breathing [13]. However, due to a longer sampling time, this will add a component of temporal averaging.

Patients are at times dyspnoeic and are frequently limited in their capacity to hold their breath which would favour the use of the free breathing technique or an alternative with the shortest breath hold. Since there is no agreement on which MRI phase-contrast technique to prefer, we hypothesized that the accuracy of volume flow measurements obtained with segmented phase-contrast during breath holding, and in particular higher number of k-space segments, would be non-inferior compared to navigator phase-contrast which has potential to become a standard of reference. Volumes obtained from anatomic segmentation of cine MRI and Doppler echocardiography were used for additional reference.

\section{Methods}

Forty patients, five women and 35 men, mean age 65 years (range 53-80), were randomly selected and gave written consent to the study (Table 1), which was approved by the Regional Ethics Committee in Linkoping, Dnr M216-09. All were part of the Doppler-cip study and had undergone a cardiac MRI scan and a transthoracic Doppler echocardiography within 2 days $[14,15]$. MRI was performed with a Philips Achieva Nova Dual $R$ 3.2, $1.5 \mathrm{~T}$ system, with a 5-element phased array cardiac coil (Philips Healthcare, Best, the Netherlands) and Doppler echocardiography with a GE Vivid 7 ultrasound scanner (GE Healthcare, Horten, Norway).

The MR flow slice was positioned transverse to the ascending aorta cranial to the sino-tubular junction where the flow is parallel to the long-axis of the body in order to obtain through-plane flow perpendicular to the slice. The acquisition was retrospectively gated to the EKG using the following parameters: slice thickness $8 \mathrm{~mm}$, field of view (FOV) $320 \times 260 \mathrm{~mm}$, acquisition matrix $128 \times 104$ (reconstructed to $256 \times 256$ ), sensitivity encoding (SENSE) factor 2, velocity encoding $200 \mathrm{~cm} / \mathrm{s}$, repetition time $4.6 \mathrm{~ms}$ and echo time $2.7 \mathrm{~ms}$. The effect on scan duration of using three different k-space segmentation factors (TFE) was studied. Scans with TFE factor of 5 and 3 were acquired in breath hold while free breathing with navigator triggering $(6 \mathrm{~mm}$ gate and track window, continuous level drift) was used for TFE 1 . The number of reconstructed cardiac phases was adjusted to the heart rate and k-space segmentation factor, e.g. from 16 (at TFE 5 and 80 beats/min) to 80 (at TFE 1 and 40 beats/min). Depending on the heart rate, the duration of breath holding could vary between $9 \mathrm{~s}$ (TFE 5,80 beats/ min) up to $28 \mathrm{~s}$ (TFE 3,40 beats $/ \mathrm{min}$ ). The navigator scan took from $42 \mathrm{~s}$ (TFE 1,80 beats/min) to $1: 24 \mathrm{~min}$ (TFE 1, 40 beats/min). All velocity data was corrected for concomitant gradient effects on the scanner as suggested by Bernstein et al [16]. Background offset due to eddy current effects was corrected on the scanner by using the default local phase correction algorithm, which

\begin{tabular}{lll} 
Table 1 Demographic data for the patients in the study & \\
\hline Demographic data & Age, mean (SD), years & $65(7)$ \\
& Female, n (\%) & $6(15)$ \\
& Body mass index, mean (SD) kg/m2 & $26.5(3.7)$ \\
Medical history & Diabetes, n (\%) & $8(20)$ \\
& Hypertension, n (\%) & $14(35)$ \\
& Myocardial infarction, n (\%) & $22(55)$ \\
& CABG, n (\%) & $9(23)$ \\
& PCl, n (\%) & $18(45)$ \\
& Moderate MR (1) or AR (1) at Doppler & $6(15)$ \\
\hline
\end{tabular}


Table 2 Stroke volume and cardiac output results

\begin{tabular}{lcccc}
\hline & Stroke volume $(\mathrm{ml})$ & Scan duration $(\mathrm{s})$ & Heart rate (beats/min) & Cardiac output $(\mathrm{ml} / \mathrm{min})$ \\
\hline Cine segmented & $91.2+/-20.8$ & & $66+/-8.8$ & $5964+/-1452$ \\
Phase contrast TF5 & $77.9+/-16.4$ & $11+/-1$ & $66+/-9.4$ & $5142+/-1197$ \\
Phase contrast TFS & $77.7+/-17.5$ & $17+/-2$ & $64+/-8.6$ & $4979+/-1211$ \\
Phase contrast (navigator) & $79.7+/-17.1$ & $50+/-6$ & $64+/-7.8$ & $5071+/-1192$ \\
\hline
\end{tabular}

Mean value and SD (standard deviation) for stroke volume and cardiac output for anatomical calculation from cine MRI and the three phase-contrast techniques

is based on an optimized spatial low pass filter (Philips Healthcare internal white paper April 12, 2012).

In addition to flow, anatomical volume measurements were performed on cine SSFP short axis images covering the left ventricle from base to apex. Slice thickness was $8 \mathrm{~mm}$ and slice gap $2 \mathrm{~mm}$. Temporal resolution ranged between 26 and $41 \mathrm{~ms}$ (30 acquired phases).

Data analysis was performed on a separate workstation using software from the vendor (Philips Extended MR Workspace, version 2.6.6.3). For flow measurements, an elliptical template covering the aortic perimeter was applied and adapted to the vessel using an active contourseeking algorithm. After manual correction, the segmentation was migrated to adjacent time frames using the active contour-seeking algorithm until the entire cardiac cycle was covered. Manual corrections were applied whenever necessary. The volume flow was calculated by temporal integration of the velocities within the segmented area, using the antegrade flow component (all forward flow components in the entire heart cycle, without deducting backward flow components) to facilitate a comparison with Doppler echocardiography and cine MRI. Cardiac output was computed as stroke volume multiplied with heart rate. Differences in heart rate between the three flow acquisitions were calculated and the largest individual difference averaged between all patients.

Anatomical MRI-based stroke volume was determined by manually segmenting the stack of short axis images of the left ventricle, in end diastole as well as in end systole. End systole was determined from the smallest ventricular area of a mid-ventricular slice, or, in case of dyssynchrony, from the time point closest to end systole determined from aortic closure in the apical long axis view [17]. The papillary muscles were included in the volume of the left ventricular cavity and the outflow tract was excluded [17]. The measurements were done in duplicate and the mean value was used in the comparisons. The duplicate measurements were used to report intraobserver reproducibility. Interobserver variability was reported from ten studies segmented by a second observer. Further data on reproducibility have been published elsewhere [14].

All patients underwent Doppler echocardiography. Stroke volume was calculated from the area of the left ventricular outflow tract (LVOT), determined from the inner-edge to inner-edge diameter according to recommendations from the European Association of Cardiovascular Imaging [2], and multiplied with the velocity time integral (VTI) determined at the level of the diameter measurement but not requiring the presence of a valve opening artefact. Pulmonary shadowing preventing the delineation of the LVOT was considered a criterion for excluding the measurement as well as excessive VTI due to placement of the sample volume in the aortic annulus. Since the echocardiogram typically was performed two days after the MRI scan, heart rate differed somewhat which necessitated using cardiac output for the comparisons.

\section{Statistical analysis}

All measurements were reasonably well normally distributed which allowed Student's $t$-test to be used for tests of statistical significance. A $p$-value of $<0.05$ was considered significant. For differences between methods, analysis according to Bland-Altman and linear regression was used. Percent values were given based on the difference of the averages. Descriptive statistics were reported as mean values with 1 standard deviation (SD).

Table 3 Stroke volume and cardiac output, mean difference between the three phase-contrast techniques

\begin{tabular}{ccc}
\hline $\begin{array}{c}\text { Comparison } \\
\text { of methods }\end{array}$ & $\begin{array}{c}\text { Stroke volume }(\mathrm{ml}) \\
\text { Mean difference, }+ \text { /-STD }\end{array}$ & $\begin{array}{c}\text { Cardiac output }(\mathrm{ml} / \mathrm{min}) \\
\text { Mean difference, }+ \text { /-STD }\end{array}$ \\
\hline TF5/TF3 & 0.2 & 163 \\
$+/-4.6$ & $+/-395$ \\
& $p=0.76$ & $p=0.013$ \\
Nav/TF3 & 2.0 & 92 \\
& $+/-6.1$ & $+/-394$ \\
& $p=0.046$ & $p=0.15$ \\
Nav/TF5 & 1.8 & -71 \\
$+/-6.8$ & $+/-462$ \\
& $p=0.10$ & $p=0.33$ \\
\hline
\end{tabular}

The mean difference between the phase-contrast based methods. The difference between TF5 ( $k$-space segmentation factor 5 ) and TF3 ( $k$-space segmentation factor 3 ) was non-significant $(p=0.76)$ for stroke volume but significant for cardiac output $(p=0.013)$. The difference between navigator vs TF3 as well as navigator vs TF5 was non-significant for cardiac output but barely significant for navigator vs TF3 for stroke volume 


\section{Results}

Stroke volume and cardiac output from phase-contrast MRI In navigator based, EKG-gated free-breathing phasecontrast flow, mean stroke volume and cardiac output were $79.7 \pm 17.1 \mathrm{ml}$ and $5071 \pm 1192 \mathrm{ml} / \mathrm{min}$, respectively (Table 2). The duration of the acquisition was $50 \pm$ $6 \mathrm{~s}$. With TFE 3 , the corresponding values were $77.7 \mathrm{ml} \pm$ $17.5 \mathrm{ml}$ and $4979 \pm 1211 \mathrm{ml} / \mathrm{min}$. The duration of the breath hold was $17 \pm 2$ s. Using TFE 5, mean stroke volume, cardiac output and breath hold time was $77.9 \pm$ $16.4 \mathrm{ml}, 5142 \pm 1197 \mathrm{ml} / \mathrm{min}$, and $11 \pm 1 \mathrm{~s}$, Table 2 . The mean difference between the three methods is depicted in Table 3 and Figs. 1 and 2 (regression and Bland-Altman). Flow with k-space segmentation factor 5 did not differ from k-space segmentation factor $3(p=0.76)$ for stroke volume, but was larger for cardiac output $(p=0.013)$.
Navigator based flow did not differ from TF3 or TF5 for cardiac output, but was barely larger for navigator vs TF3 for stroke volume $(p=0.046)$.

\section{Stroke volume and cardiac output based on left ventricular volumes from cine SSFP MRI}

Mean stroke volume and cardiac output were $91.2 \pm$ $20.8 \mathrm{ml}$ and $5963 \pm 1452 \mathrm{ml} / \mathrm{min}$, respectively, Table 1 . Intraobserver reproducibility expressed as coefficient of variation (SD divided by the mean) was $4 \%$ for LVEDV, $8 \%$ for LVESV and $7 \%$ for stroke volume. The corresponding values for interobserver variability calculated from segmenting 10 patients was $6.4 \%$ for LVEDV, $11.2 \%$ for LVESV and $7.6 \%$ for stroke volume. Interobserver bias and limits of agreement for stroke volume was in this subsample $1.9 \pm 13.4 \mathrm{ml}$.

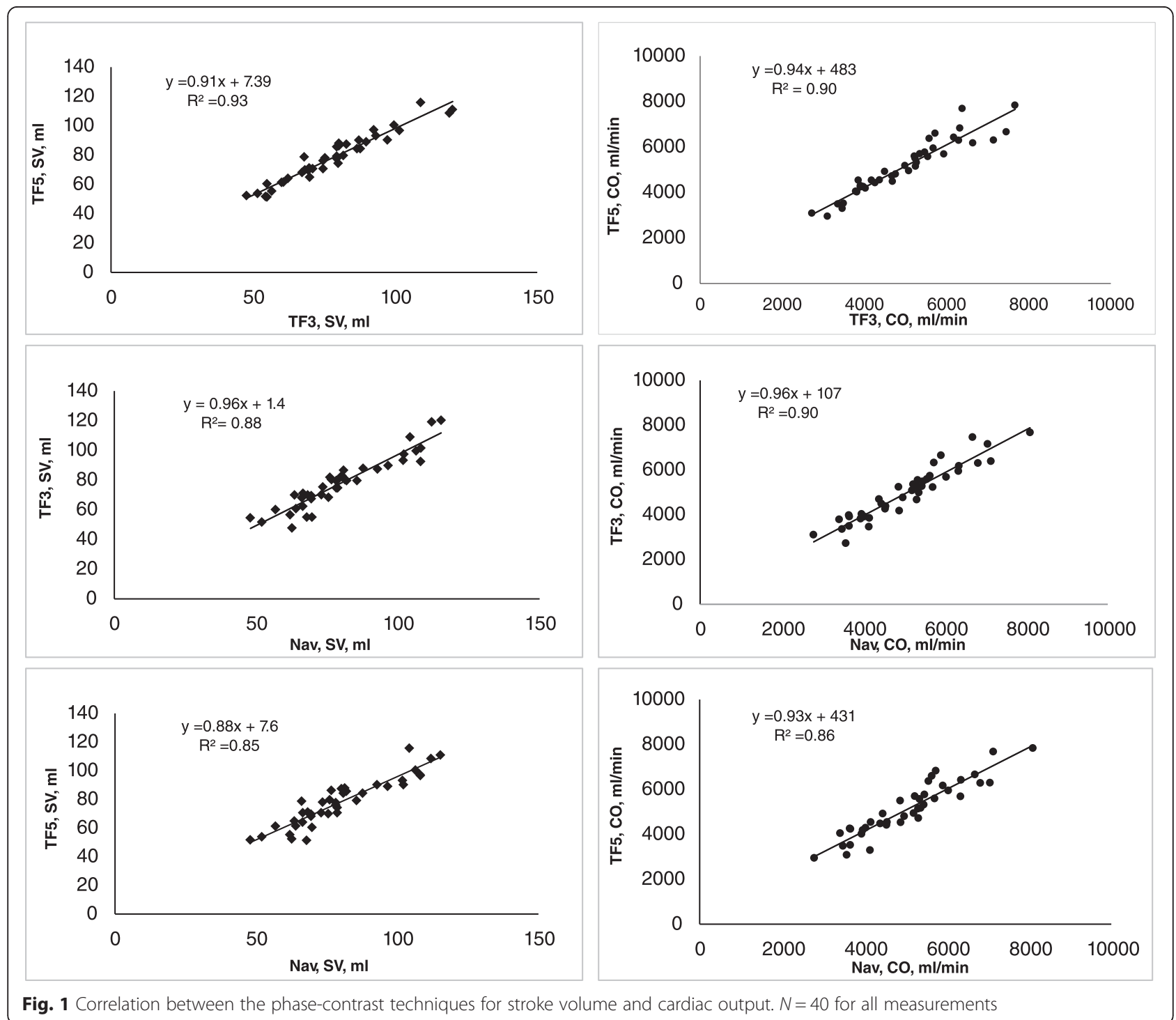



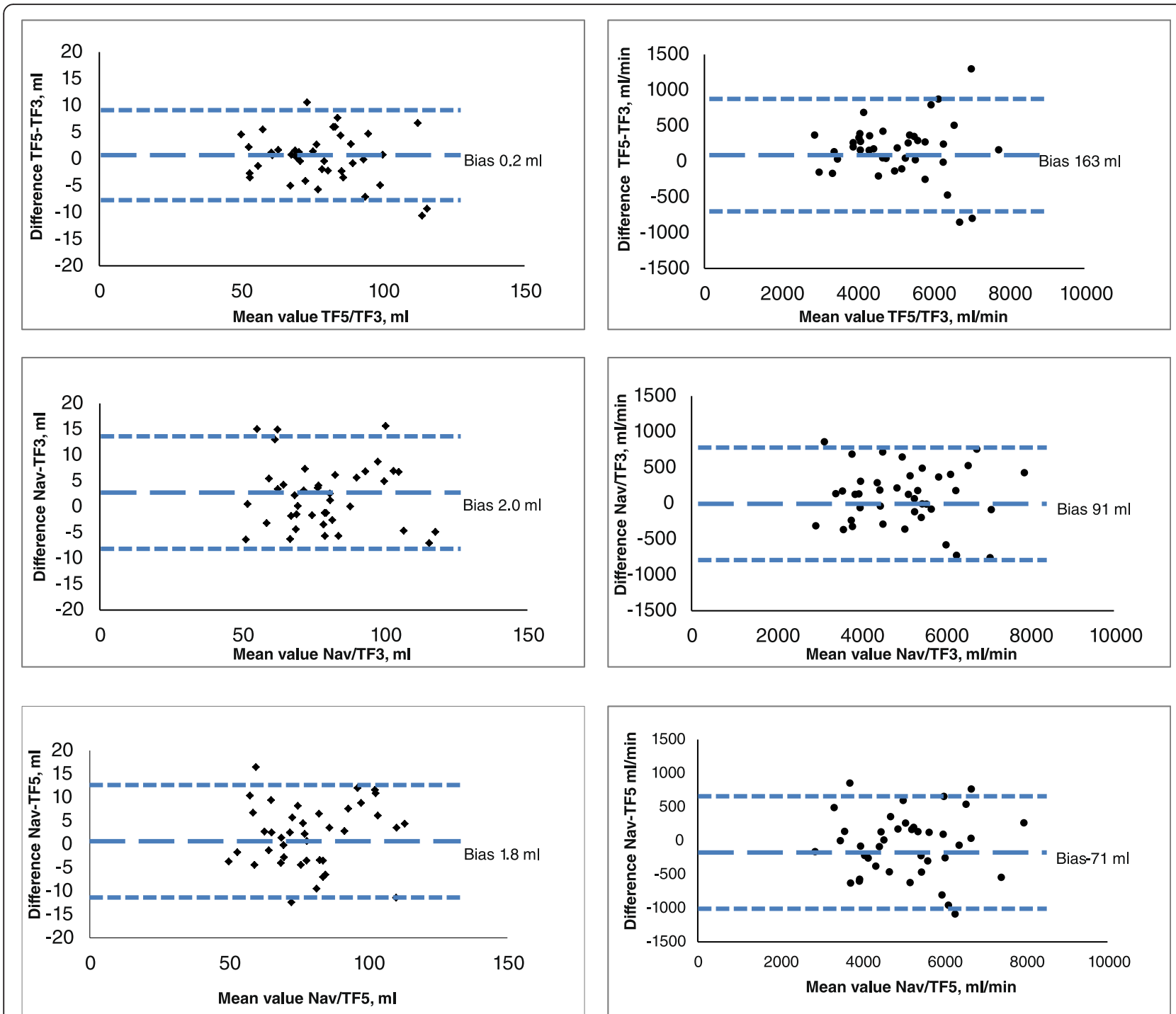

Fig. 2 Bland-Altman diagram depicting stroke volume and cardiac output for the three phase-contrast techniques. $N=40$ for all measurements. Bias and limits of agreements are given in dashed blue

\section{Doppler Echocardiography for flow measurement}

Twenty patients were excluded due to either unreliable diameter measurements of the left ventricular outflow tract or inappropriate placement of the sample volume causing an overestimation of the velocity time integral. In the remaining 20 patients, the mean diameter of the left ventricular outflow tract was $20.7 \pm 1.5 \mathrm{~mm}$, stroke volume $78.3 \mathrm{ml} \pm 15.2 \mathrm{ml}$ and cardiac output $5164 \pm$ $1249 \mathrm{ml} / \mathrm{min}$. A comparison with navigator flow data is given in Fig. 3.

\section{Effects of heart rate}

Even over shorter periods of time, heart rate varies with anxiety/arousal of the patient. In this study, individual heart rates differed substantially between the different acquisitions, the largest difference in a particular patient being 31 beats/min. The lowest difference between any of the acquisitions in one individual was 4 beats/min. The average largest difference for all individuals was $11.3 \pm 5.9$ beats $/ \mathrm{min}$, but in a group-wise comparison, these individual differences are not apparent on the mean values (Table 2).

\section{Discussion}

This study shows that measuring aortic flow during short breath holds is feasible, despite concern that breath holding might affect cardiac filling. All measurement methods are prone to biological variation and inherent variation in accuracy and repeatability [18]. Some measurements require the full cooperation of patients, at times exceeding their limits e.g. when holding breath in obstructive pulmonary disease. For a long time, MRI 


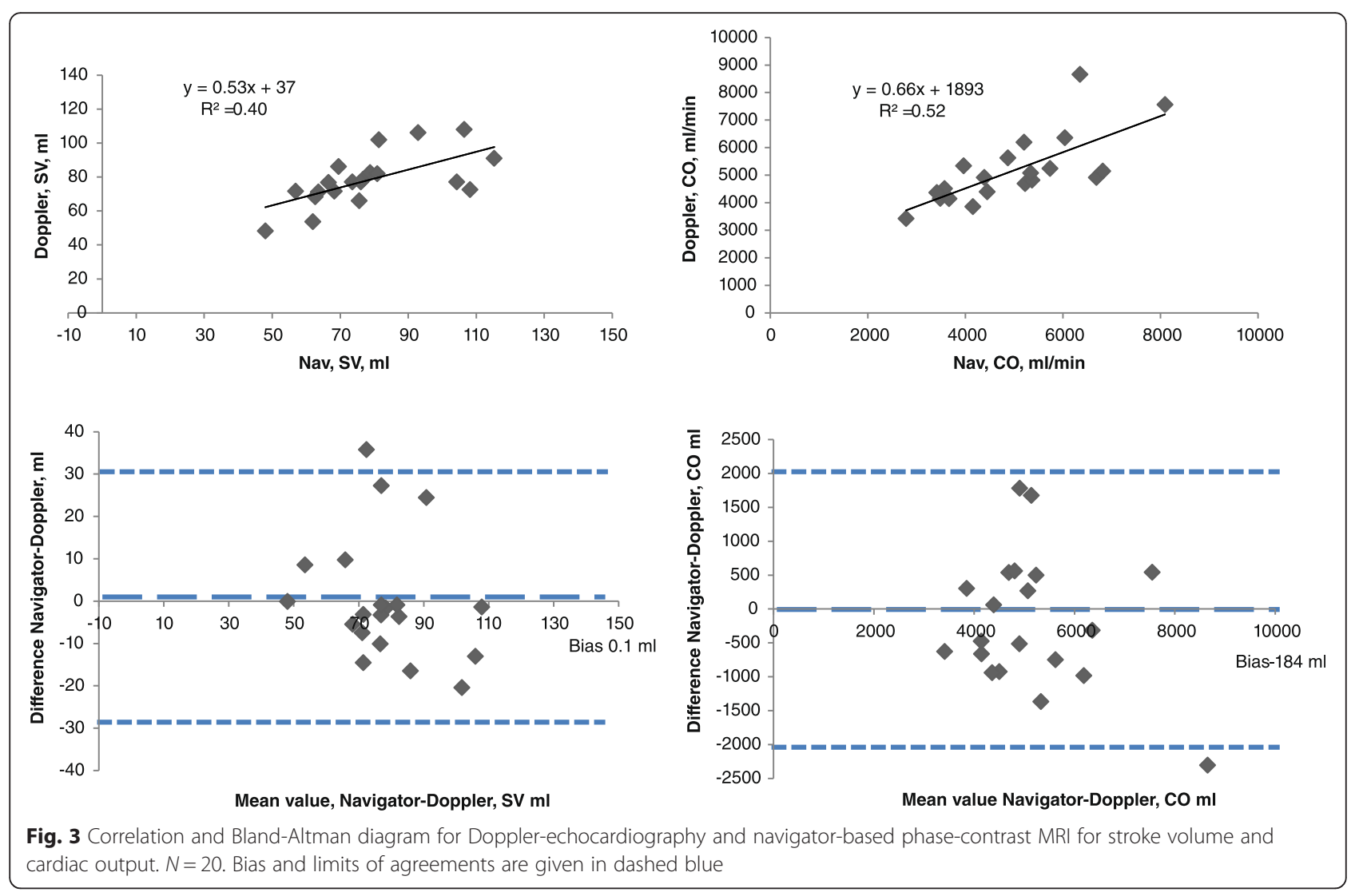

phase-contrast has been considered the gold standard in the non-invasive determination of stroke volume and cardiac output $[19,20]$. However, MRI can be executed in many different ways. In general, methods that shorten the time required for the collection of data are attractive since they ease the demands on the patient thereby facilitating work flow.

In this study comparing free breathing and breath hold recording of aortic flow, we found that the mean difference was below $2 \mathrm{ml}(2.5 \%)$ for stroke volume and below $163 \mathrm{ml} / \mathrm{min}(3.2 \%)$ for cardiac output, which we consider acceptable for everyday clinical practice (Fig. 2, Table 3). Individual differences are also within clinically acceptable levels, with $55-75 \%$ in the interval $\pm 5 \mathrm{ml}$ for stroke volume and $67-82 \% \pm 500 \mathrm{ml} / \mathrm{min}$ for cardiac output in Bland-Altman analysis (Fig. 2). Close to one minute acquisition time for the free breathing sequence may seem short, but the breath held techniques are considerably quicker, without significant errors in measurement. When choosing between the two levels of k-space segmentation (TFE factors 3 and 5) TFE 5 was $5 \mathrm{~s}$ faster which may seem little, but for an ill patient, holding breath for $11 \mathrm{~s}$ is a lot easier than holding breath for $16 \mathrm{~s}$.

All patients provided evaluable phase-contrast flow results, with mean values within $2 \%$ to that from the Doppler echocardiography results when available (Table 3).
However, in Doppler echocardiography an inability to determine the LVOT diameter and a tendency towards overestimation of VTI caused many exclusions. Three-dimensional techniques have demonstrated that the LVOT is elliptical [2] and the spatial flow profile of the LVOT has been demonstrated to be skewed in healthy individuals and in patients with aortic regurgitation [3]. These conditions may have contributed to an inaccurate determination of stroke volume in the present study.

The largest difference found was between the flow based techniques and the anatomically determined MRI flow volume. Few patients in this study (5 MI, $1 \mathrm{AI}$ ) had more than trace mitral or aortic regurgitation (Table 1). It has been hypothesized that the combination of coronary blood flow not being included in the phase-contrast aortic sampling and the presence of unrecognized mitral regurgitation may explain a large part of the difference between phase-contrast and anatomic flow values $[17,21]$.

\section{Relation to earlier studies}

In healthy volunteers Polte et al found a bias of $12 \mathrm{ml}$ and limits of agreement of $0-24 \mathrm{ml}$ between anatomic and phase-contrast stroke volumes [22]. Likewise, James et al. found $5-7 \mathrm{ml}$ difference in anatomical vs phasecontrast stroke volume that was attributed to coronary 
flow [23]. Differences between anatomically based measurements were also found in a recent multi-modality study of LVEDV with smaller 2D- and 3D-echo volumes than those obtained with the goldstandard MRI [23, 24]. Even with the high image quality obtained with SSFP and despite use of a meticulous segmentation technique, there will always be need for training [25] to overcome difficulties in the definition of the most basal slice of the left ventricle and the definition of the endocardial border in the presence of trabeculae. Suinesiaputra et al have recently recommended systematic training on a specific dataset to improve on the result of manual segmentation. However, the reproducibility of segmentation in the Doppler-cip study, of which the data here presented is a subset, has been extensively discussed in a previous publication, with interobserver bias and LOA of $8.2+7.7 \mathrm{ml}$ for stroke volume [26]. The recommendations on segmentation are still subject to changes [17].

\section{Conclusions}

In forty consecutive patients with coronary heart disease, using breath holding and segmented k-space sampling techniques for phase-contrast flow produced stroke volumes and cardiac outputs similar to those obtained with free breathing navigator based phase-contrast MRI, using less time. The values obtained agreed fairly well with Doppler echocardiography while there was a larger difference when compared with anatomical volume determinations using SSFP MRI.

\section{Availability of supporting data}

Due to statutory provisions regarding data- and privacy protection, the dataset supporting the conclusions of this article is available upon individual request directed to the corresponding author.

\section{Abbreviations}

LVEDV: left ventricular end diastolic volume; MRI: magnetic resonance imaging; SENSE: sensitivity encoding; SSFP: Steady State Free Precession; TFE: turbo field echo.

\section{Competing interests}

The authors declare that they have no competing interests.

\section{Authors' contributions}

CA and JE have been involved in conception and design. JE recruited the subjects. JE and JK have been involved in data acquisition. CA and JE have post processed the data. CA, JE, TE and CJC analyzed and interpreted the data. CA has performed the statistical analysis. JE has supervised the study. CA and JE drafted the manuscript. CA, JK, TE, LL, CJC and JE critically revised the manuscript. All authors had full access to the data and take responsibility for its integrity. All authors have read and agree to the manuscript as written.

\section{Acknowledgements}

This research was partly funded by the Swedish Heart and Lung Foundation (grants no 20120449 and 20140398), the Region of Östergötland (grant no 281281), the European Union FP 7 (grant no 223615) and the Medical Research Council of Southeast Sweden (grants no 88731 and 157921). The
MRI technicians of CMIV and research technician Gunborg Gidby are gratefully acknowledged for performing the patient studies.

\section{Author details}

${ }^{1}$ Center for Medical Image Science and Visualization, Linkoping University, SE-581 83 Linkoping, Sweden. ${ }^{2}$ Department of Clinical Physiology, Linkoping University, SE-603 79 Norrkoping, Sweden. ${ }^{3}$ Department of Diagnostic Radiology, Linkoping University, SE-581 85 Linkoping, Sweden. ${ }^{4}$ Department of Medical and Health Sciences, Linkoping University, SE-581 83 Linkoping, Sweden. ${ }^{5}$ Department of Clinical Physiology, Linkoping University, SE-581 85 Linkoping, Sweden.

Received: 31 March 2015 Accepted: 21 March 2016

Published online: 28 March 2016

\section{References}

1. Richter $Y$, Edelman ER. Cardiology is flow. Circulation. 2006;113:2679-82.

2. Lang RM, Badano LP, Mor-Avi V, Afilalo J, Armstrong A, Ernande L, Flachskampf FA, Foster E, Goldstein SA, Kuznetsova T, et al. Recommendations for cardiac chamber quantification by echocardiography in adults: an update from the American Society of Echocardiography and the European Association of Cardiovascular Imaging. Eur Heart J Cardiovasc Imaging. 2015;16:233-70

3. Sjoberg BJ, Ask P, Loyd D, Wranne B. Subaortic flow profiles in aortic valve disease: a two-dimensional color Doppler study. J Am Soc Echocardiogr. 1994;7:276-85.

4. Moran PR. A flow velocity zeugmatographic interlace for NMR imaging in humans. Magn Reson Imaging. 1982;1:197-203.

5. Pelc NJ, Herfkens RJ, Shimakawa A, Enzmann DR. Phase contrast cine magnetic resonance imaging. Magn Reson Q. 1991;7:229-54.

6. Gatehouse PD, Rolf MP, Bloch KM, Graves MJ, Kilner PJ, Firmin DN, Hofman MB. A multi-center inter-manufacturer study of the temporal stability of phase-contrast velocity mapping background offset errors. J Cardiovasc Magn Reson. 2012;14:72.

7. Gatehouse PD, Rolf MP, Graves MJ, Hofman MB, Totman J, Werner B, Quest RA, Liu Y, von Spiczak J, Dieringer M, et al. Flow measurement by cardiovascular magnetic resonance: a multi-centre multi-vendor study of background phase offset errors that can compromise the accuracy of derived regurgitant or shunt flow measurements. J Cardiovasc Magn Reson. 2010;12:5.

8. Chernobelsky A, Shubayev O, Comeau CR, Wolff SD. Baseline correction of phase contrast images improves quantification of blood flow in the great vessels. J Cardiovasc Magn Reson. 2007;9:681-5.

9. Luk Pat GT, Pauly JM, Hu BS, Nishimura DG. One-shot spatially resolved velocity imaging. Magn Reson Med. 1998;40:603-13.

10. Johansson B, Babu-Narayan SV, Kilner PJ. The effects of breath-holding on pulmonary regurgitation measured by cardiovascular magnetic resonance velocity mapping. J Cardiovasc Magn Reson. 2009;11:1.

11. Ley S, Fink C, Puderbach M, Zaporozhan J, Plathow C, Eichinger M, Hosch W, Kreitner KF, Kauczor HU. MRI Measurement of the hemodynamics of the pulmonary and systemic arterial circulation: influence of breathing maneuvers. AJR Am J Roentgenol. 2006;187:439-44.

12. Sakuma H, Kawada N, Kubo H, Nishide Y, Takano K, Kato N, Takeda K. Effect of breath holding on blood flow measurement using fast velocity encoded cine MRI. Magn Reson Med. 2001;45:346-8.

13. Chai $P$, Mohiaddin R. How we perform cardiovascular magnetic resonance flow assessment using phase-contrast velocity mapping. J Cardiovasc Magn Reson. 2005;7:705-16.

14. Queiros S, Barbosa D, Engvall J, Ebbers T, Nagel E, Sarvari SI, Claus P, Fonseca JC, Vilaca JL, D'Hooge J. Multi-centre validation of an automatic algorithm for fast 4D myocardial segmentation in cine CMR datasets. Eur Heart J Cardiovasc Imaging. 2015. [Epub ahead of print] PMID:26494877.

15. Rademakers F, Engvall J, Edvardsen $T$, Monaghan M, Sicari R, Nagel E, Zamorano J, Ukkonen H, Ebbers T, Di Bello V, et al. Determining optimal noninvasive parameters for the prediction of left ventricular remodeling in chronic ischemic patients. Scand Cardiovasc J. 2013:47:329-34.

16. Bernstein MA, Zhou XJ, Polzin JA, King KF, Ganin A, Pelc NJ, Glover GH. Concomitant gradient terms in phase contrast MR: analysis and correction. Magn Reson Med. 1998;39:300-8. 
17. Schulz-Menger J, Bluemke DA, Bremerich J, Flamm SD, Fogel MA, Friedrich MG, Kim RJ, von Knobelsdorff-Brenkenhoff F, Kramer CM, Pennell DJ, et al. Standardized image interpretation and post processing in cardiovascular magnetic resonance: Society for Cardiovascular Magnetic Resonance (SCMR) board of trustees task force on standardized post processing. J Cardiovasc Magn Reson. 2013;15:35.

18. Douglas GA, Altman J. Practical statistics for medical research. London: Chapman \& Hall; 1991. p. 365-95.

19. Gatehouse PD, Keegan J, Crowe LA, Masood S, Mohiaddin RH, Kreitner KF, Firmin DN. Applications of phase-contrast flow and velocity imaging in cardiovascular MRI. Eur Radiol. 2005;15:2172-84.

20. Pennell DJ, Sechtem UP, Higgins CB, Manning WJ, Pohost GM, Rademakers FE, van Rossum AC, Shaw L, Yucel EK, Society for Cardiovascular Magnetic R, Working Group on Cardiovascular Magnetic Resonance of the European Society of C. Clinical indications for cardiovascular magnetic resonance (CMR): Consensus Panel report. Eur Heart J. 2004;25:1940-65.

21. Uretsky S, Gillam L, Lang R, Chaudhry FA, Argulian E, Supariwala A, Gurram S, Jain K, Subero M, Jang JJ, et al. Discordance between echocardiography and MRI in the assessment of mitral regurgitation severity: a prospective multicenter trial. J Am Coll Cardiol. 2015;65:1078-88.

22. Polte $\mathrm{CL}$, Bech-Hanssen O, Johnsson AA, Gao SA, Lagerstrand KM. Mitral regurgitation quantification by cardiovascular magnetic resonance: a comparison of indirect quantification methods. Int J Cardiovasc Imaging. 2015;31:1223-31.

23. James SH, Wald R, Wintersperger BJ, Jimenez-Juan L, Deva D, Crean AM, Nguyen E, Paul NS, Ley S. Accuracy of right and left ventricular functional assessment by short-axis vs axial cine steady-state free-precession magnetic resonance imaging: intrapatient correlation with main pulmonary artery and ascending aorta phase-contrast flow measurements. Can Assoc Radiol J. 2013;64:213-9

24. Greupner J, Zimmermann E, Grohmann A, Dubel HP, Althoff TF, Borges AC, Rutsch W, Schlattmann P, Hamm B, Dewey M. Head-to-head comparison of left ventricular function assessment with 64-row computed tomography, biplane left cineventriculography, and both 2- and 3-dimensional transthoracic echocardiography: comparison with magnetic resonance imaging as the reference standard. J Am Coll Cardiol. 2012:59:1897-907.

25. Karamitsos TD, Hudsmith LE, Selvanayagam JB, Neubauer S, Francis JM. Operator induced variability in left ventricular measurements with cardiovascular magnetic resonance is improved after training. J Cardiovasc Magn Reson. 2007;9:777-83.

26. Suinesiaputra A, Bluemke DA, Cowan BR, Friedrich MG, Kramer CM, Kwong R, Plein S, Schulz-Menger J, Westenberg JJ, Young AA, Nagel E. Quantification of LV function and mass by cardiovascular magnetic resonance: multi-center variability and consensus contours. J Cardiovasc Magn Reson. 2015;17:63.

\section{Submit your next manuscript to BioMed Central and we will help you at every step:}

- We accept pre-submission inquiries

- Our selector tool helps you to find the most relevant journal

- We provide round the clock customer support

- Convenient online submission

- Thorough peer review

- Inclusion in PubMed and all major indexing services

- Maximum visibility for your research

Submit your manuscript at www.biomedcentral.com/submit

) Biomed Central 